GEOFIZIKA VOL. $37 \quad 2020$

DOI: https://doi.org/10.15233/gfz.2020.37.6

Original scientific paper

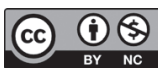

\title{
Multivariable teaching-learning-based optimization (MTLBO) algorithm for estimating the structural parameters of the buried mass by magnetic data
}

\author{
Ata Eshaghzadeh ${ }^{1}$ and Sanaz Seyedi Sahebari ${ }^{2}$ \\ ${ }^{1}$ Department of Geology, Faculty of Sciences, University of Isfahan, Isfahan, Iran \\ ${ }^{2}$ Roshdiyeh Higher Education Institute, Tabriz, Iran
}

Received 28 March 2020, in final form 1 August 2020

\begin{abstract}
This paper presents a nature-based algorithm, titled multivariable teaching-learning-based optimization (MTLBO) algorithm. MTLBO algorithm during an iterative process can estimates the best values of the buried structure (model) parameters in a multi-objective problem. The algorithm works in two computa-tional phases: the teacher phase and the learner phase. The major purpose of the MTLBO algorithm is to modify the value of the learners and thus, improving the value of the model parameters which leads to the optimal solution. The variables of each learner (model) are the depth $(z)$, amplitude coefficient $(k)$, shape factor $(q)$, angle of effective magnetization $(\theta)$ and axis location $\left(x_{0}\right)$ parameters. We employ MTLBO method for the magnetic anomalies caused by the buried structures with a simple geometric shape such as sphere and horizontal cylinder. The efficiency of the MTLBO is also studied by noise corruption synthetic data, as the acceptable results were obtained. We have applied the MTLBO for the interpretation of the four magnetic anomaly profiles from Iran, Brazil and India.
\end{abstract}

Keywords: magnetic, MTLBO algorithm, optimization, multi-objective problem

\section{Introduction}

Magnetic field measurement is a main geophysical approach for investigating the buried geological structure whose magnetism is strong. There are different objectives for magnetic data survey, such as hydrocarbon and mineral exploration, engineering evaluations, geothermal studies, archaeological site considerations and hydrological investigations.

Several qualitative approaches for magnetic data processing and various quantitative interpretative methods have been developed for estimating the 
geometric parameters values such as width, dip, amplitude coefficient and depth and position of the magnetic anomaly causative mass, such as Werner deconvolution (Jain, 1976), Euler deconvolution (Thompson, 1982; Reid et al., 1990), least-squares minimization approach (Abdelrahman et al., 2003 and 2009; AboEzz and Essa, 2016), nonlinearly mathematical optimization (Asfahani and Tlas, 2004), nonlinear inversion using stochastic algorithms (Asfahani and Tlas, 2007), parametric curves approach (Abdelrahman et al., 2012), a semi-automatic technique based on ratios of the gradients of the magnetic anomaly (Cooper, 2012), stable downward continuation (Abedi et al., 2013), ant colony optimization (Srivastava et al., 2014), combination of deconvolution technique and simplex algorithm (Tlas and Asfahani, 2015), second moving average residual anomalies (Abdelrahman and Essa, 2015; Abdelrahman et al., 2016), simulated annealing (Biswas, 2016), hybrid genetic-price algorithm (Di Maio et al., 2016), singular value decomposition (SVD) (Eshaghzadeh and Kalantari, 2016), differential evolution algorithm (Ekinci et al., 2016; Balkaya et al., 2017), global nonlinear optimization (Biswas et al., 2017), gradient methods (Essa and Elhussein, 2017a), genetic algorithm (Kaftan, 2017), particle swarm optimization (Essa and Elhussein 2017b; 2018; 2020), global optimization technique and analysis of uncertainty (Biswas, 2018), quadratic curve regression (Tlas ans Asfahani, 2018), Nelder-Mead simplex algorithm (Abdelrahman et al., 2019) and Marquardt optimization algorithm (Eshaghzadeh et al., 2020). Ekinci et al. (2020) have developed application of the particle swarm optimization (PSO), differential evolution algorithm (DEA) and differential search algorithm (DSA) for potential fields.

Teaching-learning-based optimization (TLBO) algorithm is a novel proficient optimization algorithm which has been inspired by the teaching and learning scheme of a teacher on learners in an entire classroom (Rao et al., 2011). This technique has developed as one of the simplest and most efficient approaches. Similar to other nature-extracted algorithms, TLBO is an optimization method based on a dynamic population that chooses the best teacher and learner from the initial swarm of models and enhances the solutions to attain the global solutions.

Different types of TLBO algorithms have been proposed in recent years to solve various problems. Rao and Patel (2013a, 2013b, 2013c) modified the TLBO to improve its performance and applied it to the optimization of thermal systems. Rao and Patel (2014) proposed a multi-objective improved teaching-learningbased optimization algorithm for unconstrained and constrained optimization problems. Satapathy and Naik (2014) applied the modified teaching-learningbased optimization algorithm for global numerical optimization.

An improved teaching-learning-based optimization with neighborhood search for applications of ANN has been developed by Wang et al. (2014). Chen et al. (2015) represented an improved teaching-learning-based optimization al- 
gorithm for solving global optimization problem. SAMCCTLBO is a multi-class cooperative teaching-learning-based optimization algorithm with simulated annealing (Chen et al., 2015). Self-adaptive multi-objective teaching-learning-based optimization and its application in ethylene cracking furnace operation optimization has been proposed by Yu et al. (2015). Rao (2016) published a review paper on the TLBO algorithm applications and a tutorial for beginners to solve the unconstrained and constrained optimization problems. Yu et al., (2016) propounded a constrained optimization based on improved teaching-learning-based optimization algorithm. Prakash et al. (2018) applied the quasi-oppositional selflearning TLBO algorithm for Economic load dispatch problem. The teachinglearning-based optimization algorithm was used for multi-skill resource constrained project scheduling problem by Zheng et al. (2017). Birashk et al. (2018) proposed a new optimization method, namely cellular teaching-learning-based optimization approach for dynamic multi-objective problems, while Kumar (2019) developed a new variant of teaching-learning-based optimization algorithm for global optimization problems.

In this paper, the multivariable teaching-learning-based optimization (MTLBO) method inspired by the TLBO algorithm is introduced with an aim to improve all the model variables simultaneously. MTLBO is a global floating population-based algorithm which is performed in an iterative process as at each iteration the best teacher (best model) is specified from the society population (models or leaners). We applied the MTLBO to invert several theoretical magnetic anomalies, with and without added random noise, as the acceptable results with a high accuracy were obtained. The MTLBO was also employed to the several residual magnetic anomalies from the different parts of the world.

\section{Magnetic effect due to simple geometric shapes}

Total, vertical and horizontal two dimensional magnetic field due to simple geometric sources such as sphere, horizontal cylinder and thin sheet and the first and second horizontal derivatives of the all magnetic fields due to thin sheet and geological contact are computed by (Abdelrahman and Essa, 2015; Abdelrahman et al., 2019):

$$
T(x, z)=k \frac{A z^{2}+B x+C x^{2}}{\left(x^{2}+z^{2}\right)^{q}},
$$

where $k$ is the amplitude coefficient, $z$ is the depth to the center of the buried mass, $x$ is defined as $x_{i}-x_{0}$ where $x_{i}$ is the measurement position coordinate and $x_{0}$ is the location of the buried mass along the anomaly profile, $q$ is the shape factor (for sphere $q=2.5$, for horizontal cylinder $q=2$, and for thin sheet $q=1$ ) and $A, B$, and $C$ are defined as follows: 


$$
A=\left\{\begin{array}{l}
3 \sin ^{2} \theta-1 \\
2 \sin \theta \\
-\cos \theta \\
\cos \theta \\
\cos \theta / z
\end{array}, B=\left\{\begin{array}{l}
-3 z \sin 2 \theta \\
-3 z \cos \theta \\
-3 z \sin \theta \\
2 z \sin \theta \\
-\sin \theta
\end{array}, C= \begin{cases}3 \cos ^{2} \theta-1 \text { for a sphere (total field) } \\
-\sin \theta & \text { for a sphere (vertical field) } \\
2 \cos \theta & \text { for a sphere (horizontal field) } \\
-\cos \theta & \text { for a horizontal cylinder } \\
& \text { thin sheet (FHD), geological } \\
0 & \text { contact (SHD) (all fields) } \\
& \text { for a thin sheet, geological } \\
& \text { contact (FHD) (all fields) }\end{cases}\right.\right.
$$

where $\theta$ is the angle of effective magnetization (inclination parameter).

\section{MTLBO algorithm}

Similar to most global stochastic crowd-based algorithms, such as particle swarm optimization method (PSO), genetic algorithm (GA), colony optimization and so on, MTLBO also appraises the optimal solutions with the process of crowd evolution during iterations. MTLBO algorithm scheme is based on two steps, teacher phase and learner phase. The group of learners (initial models) in a typical class space form the population. The best learner in the population is selected as the teacher. In each iteration, a new teacher is assigned.

The learners attempt to improve their knowledge (values of the model parameters) in both phases. During the teacher phase, the learners interact with the teacher to enhance their knowledge. During the learner phase, the knowledge is improved by investigation of the displacement of the parameters between the fellow learners.

In this research, the criterion of the enhancements of the knowledge at each iteration for both phases, is an objective function that evaluates the error value between the observed magnetic anomalies and generated ones using the improved parameters.

Prior to optimization process by MTLBO, the population of the learners (models) should be organized. In initialization step the primary population of size NA $\times$ NL is randomly produced, where NA indicates the dimension of the problem, i.e., the number of adjustable subjects and NL infers the length of population, i.e., number of learners.

$$
\text { Initial population } X=\left[\begin{array}{llll}
x_{k, j} & x_{k, j+1} & \ldots & x_{k, N L} \\
x_{k+1, j} & x_{k+2, j+2} & \ldots & x_{k+2, N L} \\
- & - & & - \\
- & - & & - \\
x_{N A, j} & x_{N A, j+2} & \ldots & x_{N A, N L}
\end{array}\right]
$$


For example, element indicates $k^{\text {th }}$ parameter of the $j^{\text {th }}$ learner (model).

The primary teacher is selected from among all the learners where a best fit exists between the estimated and measured magnetic data. Thus, the best solution is assigned as the teacher for the iteration. This teacher is one of the models which organize the members or population of the class. The MTLBO is a multivariable problem solver. Each model includes five variable parameters $(N A=5)$, i.e., the depth $(z)$, amplitude coefficient $(k)$, shape factor $(q)$, angle of effective magnetization $(\theta)$ and axis location $\left(x_{0}\right)$ parameters. Therefore, each main teacher includes five individual teachers as work in parallel at each iteration to improve the results of his or her assigned class (parameter).

\subsection{Teacher phase}

The objective of the teacher phase in the MTLBO is that the teacher i.e. the best solution in the entire initial population attempts to enhance the knowledge and performance of the learners so that the mean result of the class is increased. In fact, the MTLBO algorithm with assimilating the knowledge of the learners decreases the standard deviation of the variables, thus the knowledge domain of the learners and certainly the mean value of class information moves towards the optimal solutions.

The best teacher is determined from the initialization phase will try to modify the mean, $M$, of the class. For this purpose, the MTLBO computes the difference between the mean result in a particular subject of the class and the result of corresponding individual teacher $\left(\operatorname{Diff}_{-} M_{i, j}^{k}\right)$ as:

$$
\operatorname{Diff}_{-} M_{i, j}^{k}=\operatorname{rand}\left(X_{t, i, j}^{k}-T_{F} M_{i}^{k}\right),
$$

where rand is a uniformly distributed random number whose range is in between 0 and 1 . denotes the value of the individual teacher in subject $k$ of the $j^{\text {th }}$ learner and is the estimated mean value of the subject of all the learner of the class for the $i^{\text {th }}$ iteration. In TLBO algorithm, $T_{F}$ is the teaching factor where its value is taken as either 1 or 2 and specified randomly using following equation:

$$
T_{F}=\operatorname{round}[1+\operatorname{rand}(0,1)] \text {, }
$$

In the optimization algorithm a lower value of $T_{F}$ causes the more precise search in small steps and a larger value of $T_{F}$ accelerate the searching process. Based on the difference vector, the existing population is updated, as:

$$
X_{\text {new }, i, j}^{k}=X_{\text {old }, i, j}^{k}+\text { Diff }_{-} M_{i, j}^{k},
$$

where $X_{n e w, i, j}^{k}$ is new position (modified value) of the $k^{\text {th }}$ particular subject of the $j^{\text {th }}$ learner for the $i^{\text {th }}$ iteration. Parameters of $X_{n e w, i, j}^{k}$ are accepted if the estimated error value by the objective function be less than ones of the old learner, otherwise 
the previous solution is retained as the input to the learner phase. The objective function is defined as:

$$
Q=\frac{2 \sum_{i}^{N}\left|T_{i}^{o}-T_{i}^{c}\right|}{\sum_{i}^{N}\left|T_{i}^{o}-T_{i}^{c}\right|+\sum_{i}^{N}\left|T_{i}^{o}-T_{i}^{c}\right|},
$$

where $N$ is the number of the magnetic measurement point, $T_{i}^{o}$ and $T_{i}^{c}$ are the magnetic anomaly observed and calculated, respectively.

\subsection{Learner phase}

In the learner phase, the learners struggle to enhance their learning capability based on the multilateral interchanging of the learners among themselves randomly during an iterative process. Thus, learners improve their skills (values) through interaction with other learners, as an individual learner obtain new knowledge if the other individuals have more knowledge than him/her. The learning strategy to learn new information between two specific learners in the populations of the class is explained below.

The algorithm randomly selects two learners $u$ and $v$ such that $Q\left(X_{\text {new }, i, u}^{k}\right) \neq$ $Q\left(X_{n e w, i, v}^{k}\right)$. The $k^{\text {th }}$ particular subject of the $u^{\text {th }}$ learner of the matrix $X_{n e w, i, u}^{\prime k}$ is modified according the following equations based on the comparison of their objective function value, that is:

$$
\begin{aligned}
& X_{\text {new }, i, u}^{\prime k}=X_{\text {new }, i, u}^{k}+\operatorname{rand}\left(X_{\text {new }, i, u}^{k}-X_{\text {new }, i, v}^{k}\right), \text { if } Q\left(X_{\text {new }, i, u}^{k}\right)<Q\left(X_{\text {new }, i, v}^{k}\right), \\
& X_{\text {new }, i, u}^{\prime k}=X_{\text {new }, i, u}^{k}+\operatorname{rand}\left(X_{\text {new }, i, v}^{k}-X_{\text {new }, i, u}^{k}\right), \text { if } Q\left(X_{\text {new }, i, v}^{k}\right)<Q\left(X_{\text {new }, i, u}^{k}\right),
\end{aligned}
$$

where $X_{n e w, i, u}^{\prime k}$ is the adjusted value of $X_{n e w, i, u}^{k}$. The $X_{n e w, i, u}^{\prime k}$ is accepted if it eventuates to a lesser objective function value.

The inversion process repeats until the error, $Q$, in Eq. (6) descends below a predetermined allowable error or the repetition continues until the end of the considered number for iterations. Figure 1 shows the flowchart of MTLBO algorithm.

\section{Theoretical examples}

For all of the synthetic models that will be investigated, according to the defined ranges for the parameters, twenty primary models are randomly manufactured, as these ranges include the assumed values for the initial model. Moreover, the synthetic magnetic field variations were calculated in the stations with $5 \mathrm{~m}$ interval along a $200 \mathrm{~m}$ profile. The number of iteration and allowable error are assigned as 50 and 0.001 , respectively. The shape of the anomaly causative bodies is distinguished based on the evaluated shape factors using MTLBO, as 


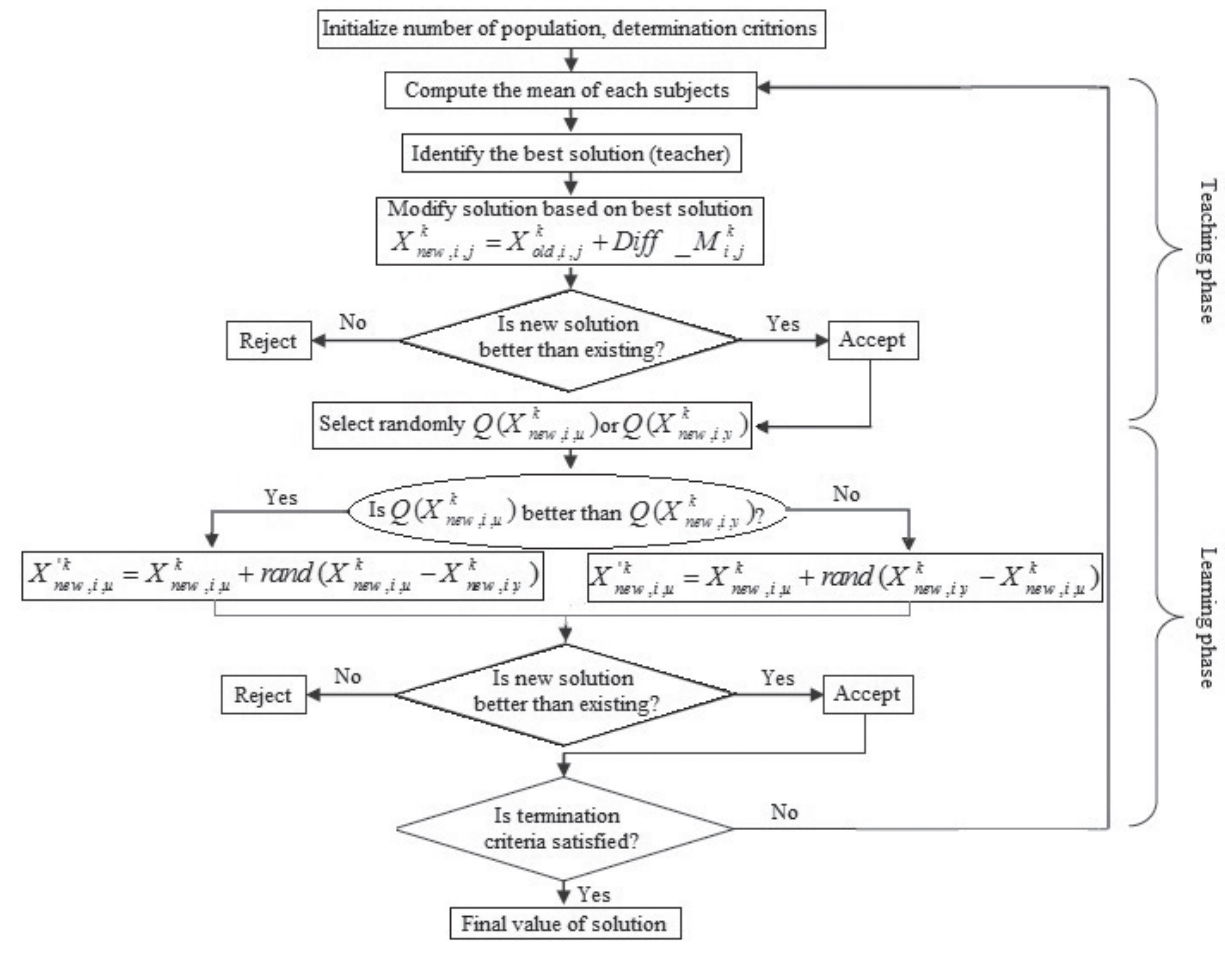

Figure 1. Flowchart of MTLBO algorithm.

for $0.5 \leq q<1.5,1.5 \leq q<2.25$ and $2.25 \leq q<3$ the buried mass shape is simulated as a vertical cylinder, horizontal cylinder and sphere, respectively.

Processing time taken by the MTLBO algorithm to detect the optimal solution for given number of iterations is accounted by a laptop with an Intel Core i5-3230M, 2.60 GHz processor, and Windows 8.1 operating system.

\subsection{Sphere model (vertical field)}

The black circles in the upper graph of Fig. 2 display the calculated theoretical magnetic field variations due to a sphere model with the parameters $z=50 \mathrm{~m}$, $\theta=75^{\circ}, k=20,000 \mathrm{nT}, q=2.5$, where the center of model is the midpoint of the profile. This magnetic anomaly was calculated using the following expression:

$$
T\left(x_{i}, z\right)=20,000 \frac{5,000 \sin \left(75^{\circ}\right)-150 x_{i} \cos \left(75^{\circ}\right)-x_{i}^{2} \sin \left(75^{\circ}\right)}{\left(x_{i}^{2}+2,500\right)^{2,5}}
$$

The search range for the parameters of the sphere model is brought in Tab. 1. The objective function value, $Q$, reduces almost intensely from its initial value 

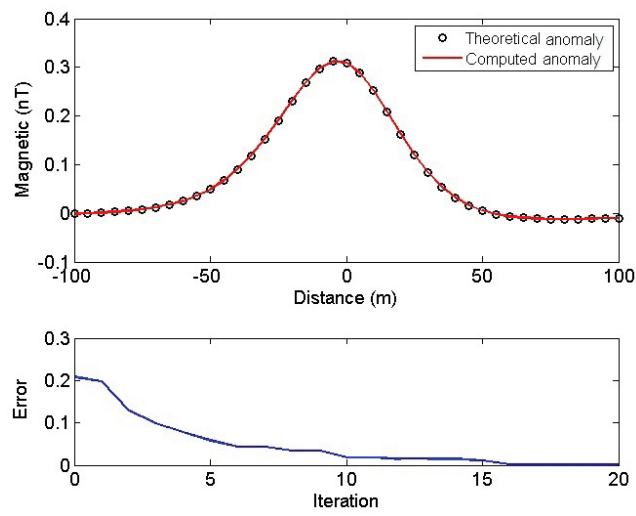

Figure 2. Synthetic magnetic anomaly over the sphere model (black circles in the upper graph) and generated magnetic from the MTLBO inversion (red curve in the upper graph). The lower graph illustrates the error improvement versus iteration number for the sphere model.

Table 1. Initial assumptions and estimated numerical results for the noise-free and noise corrupted synthetic magnetic anomaly of the sphere model.

\begin{tabular}{lcccccc}
\hline Parameter & $Q$ & $z(\mathrm{~m})$ & $\theta$ (deg.) & $k(\mathrm{nT})$ & $q$ & $x_{0}(\mathrm{~m})$ \\
\hline Assumed & - & 50 & 75 & 20000 & 2.5 & 0 \\
Ranges & - & 30 to 70 & 60 to 90 & 15000 to 25000 & 0.5 to 3 & -10 to 10 \\
Noise free & 0.00085 & 50.014 & 75.018 & 19985 & 2.5 & 0 \\
Noisy data & 0.109 & 49.012 & 77.8 & 20241 & 2.537 & -0.16 \\
\hline
\end{tabular}

of 0.21 before the first iteration to 0.047 at the end of the $6^{\text {th }}$ iteration and then gradually reaches to 0.00085 after the $20^{\text {th }}$ iteration which is smaller than the considered allowable error value (Fig. 1, blue line in the lower graph). Thus, the optimization process terminated at $20^{\text {th }}$ iteration where the estimated values of the parameters are $z=50.014 \mathrm{~m}, \theta=75.018^{\circ}, k=19,985 \mathrm{nT}, q=2.5$ and $x_{0}=0 \mathrm{~m}$. The inverted magnetic field from the MTLBO algorithm is shown by the red curve in the upper graph of the Fig. 2.

The ability of the MTLBO algorithm is studied with adding a set of random noise to the magnetic anomaly of the sphere model using the following equation:

$$
T_{\text {noise }}\left(x_{i}\right)=T_{\text {obs }}\left(x_{i}\right)+0.05 \times(R A N(i)-0.5),
$$

where $T_{\text {noise }}\left(x_{i}\right)$ is the noise corrupted synthetic data at $x_{i}$, and $R A N(i)$ is a pseudorandom number whose range is between 0 to 1 .

Figure 3 (black circles in the upper graph) displays the contaminated magnetic anomaly. The error variations versus the iteration number indicate a strong reduction from 0.284 before the first iteration to 0.123 at the end of the $9^{\text {th }}$ iteration and then slowly attains to 0.109 at the end of the $11^{\text {th }}$ iteration and this value remains constant to latest iteration as is shown by the blue line in the 

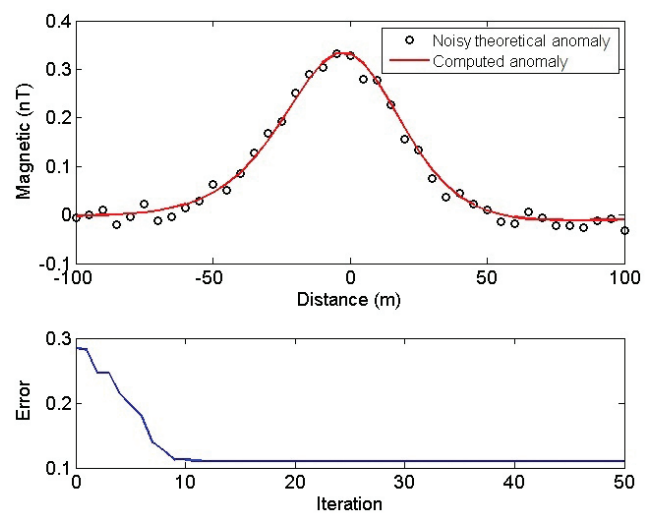

Figure 3. Noisy corrupted synthetic magnetic anomaly over the sphere model (black circles in the upper graph) and generated magnetic from the MTLBO inversion (red curve in the upper graph). The lower graph illustrates the error improvement versus iteration number for $10 \%$ noise corrupted data of the sphere model.

lower graph of Fig. 3. The resulted values for the noisy magnetic data of the sphere model using MTLBO are $z=49.012 \mathrm{~m}, \theta=77.8^{\circ}, k=20241 \mathrm{nT}, q=2.537$ and $x_{0}=-0.16 \mathrm{~m}$. The inverted magnetic field from the MTLBO algorithm has been shown in Fig. 3 (red curve in the upper graph). The assumed values for the sphere model parameters and estimated ones for the noise-free and noise corrupted synthetic magnetic data are tabulated in Tab. 1. The computation total time taken for the noise-free and noise corrupted theoretical magnetic data of the sphere model are 3.18371 and 3.59323 seconds, respectively.

\subsection{Horizontal cylinder model}

The black circles in the upper graph of Fig. 4 show the computed theoretical magnetic field variations for horizontal cylinder model with the parameters $z=40 \mathrm{~m}, \theta=45^{\circ}, k=10,000 \mathrm{nT}$ and $q=2$, where the center of the horizontal cylinder model is coincident with the center of the profile $\left(x_{0}=0\right)$. This magnetic anomaly was calculated by the following expression:

$$
T\left(x_{i}, z\right)=10,000 \frac{1,600 \cdot \cos \left(45^{\circ}\right)-80 \cdot x_{i} \cdot \sin \left(45^{\circ}\right)-x_{i}^{2} \cdot \cos \left(45^{\circ}\right)}{\left(x_{i}^{2}+1,600\right)^{2}}
$$

The defined search range for the parameters of the horizontal cylinder model is shown in Tab. 2. Considering to the blue line in the lower graph of Fig. 4, the objective function value, $Q$, decreases with a mostly gentle slope from its initial value of 0.0283 before the first iteration to 0.0067 at the end of the 18th iteration and then slowly reaches to 0.00066 after the 41 th iteration which is smaller than the acceptable error value. Thus, the optimization process stopped at 41 th iteration where the estimated values of the parameters are $z=40.03 \mathrm{~m}$, 

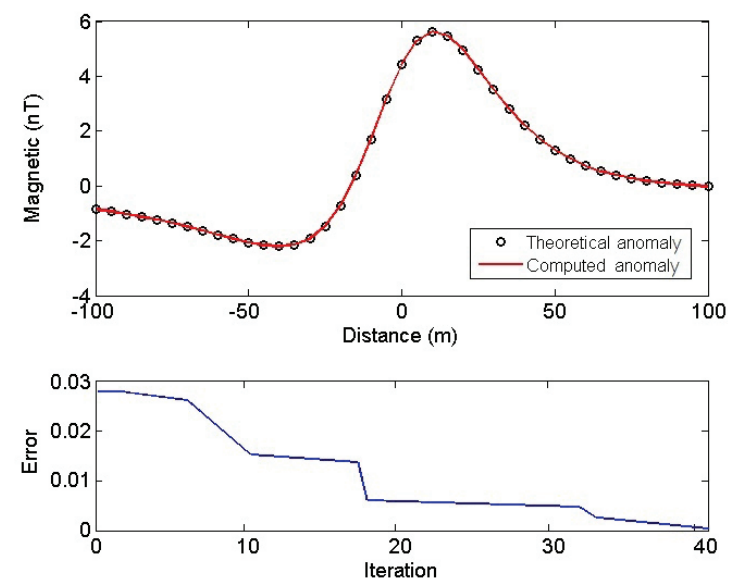

Figure 4. Synthetic magnetic anomaly over the horizontal cylinder model (black circles in the upper graph) and generated magnetic from the MTLBO inversion (red curve in the upper graph). The lower graph illustrates the error improvement versus iteration number for the horizontal cylinder model.

Table 2. Initial assumptions and estimated numerical results for the noise-free and noise corrupted synthetic magnetic anomaly of the horizontal cylinder model.

\begin{tabular}{lcccccc}
\hline Parameter & $Q$ & $z(\mathrm{~m})$ & $\theta$ (deg.) & $k(\mathrm{nT})$ & $q$ & $x_{0}(\mathrm{~m})$ \\
\hline Assumed & - & 40 & 45 & 10000 & 2 & 0 \\
Ranges & - & 20 to 60 & 25 to 65 & 7000 to 13000 & 0.5 to 3 & -10 to 10 \\
Noise free & 0.00066 & 40.03 & 44.985 & 10017 & 2.01 & 0 \\
Noisy data & 0.116 & 40.52 & 46.076 & 10134 & 1.954 & 0.35 \\
\hline
\end{tabular}

$\theta=44.985^{\circ}, k=10,017 \mathrm{nT}, q=2.01$ and $x_{0}=0 \mathrm{~m}$. The generated magnetic from the MTLBO algorithm inversion is shown in Fig. 4 (red curve in the upper graph).

We have also tested the efficiency of the MTLBO algorithm in the case of noise existence. For this purpose, a set of random noise is distributed among the magnetic data of the horizontal cylinder model using the following expression:

$$
T_{\text {noise }}\left(x_{i}\right)=T_{o b s}\left(x_{i}\right)+(R A N(i)-0.5),
$$

The black circles in the upper graph of Fig. 5 display the noise corrupted synthetic magnetic data. The error modifications versus the iteration number show an almost uniform reduction from its initial value of 0.1393 before the first iteration to 0.128 at the end of the $41^{\text {th }}$ iteration and this value remains unchanged to latest iteration (Fig. 5, blue line in the lower graph). The resulted values for the contaminated magnetic data of the horizontal cylinder model using MTLBO are $z=40.52 \mathrm{~m}, \theta=46.076^{\circ}, k=10134 \mathrm{nT}, q=1.954$ and $x_{0}=0.35 \mathrm{~m}$. The computed magnetic field from the MTLBO algorithm is shown in Fig. 6 (red 

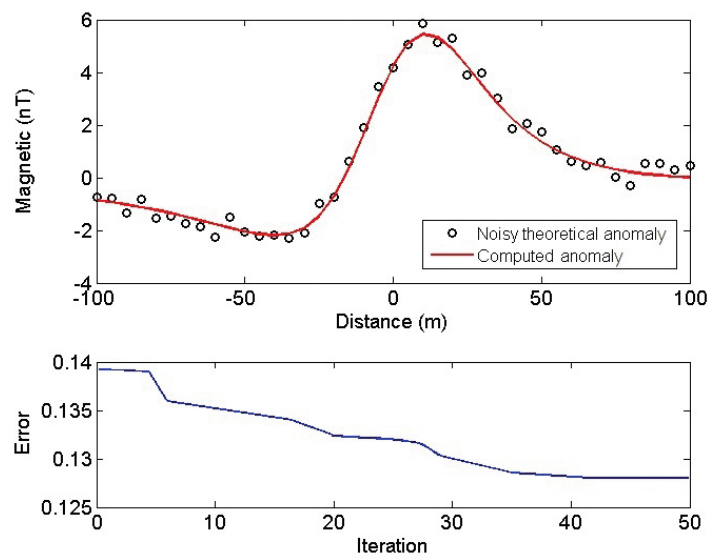

Figure 5. Noisy corrupted synthetic magnetic anomaly over the horizontal cylinder model (black circles in the upper graph) and generated magnetic field from the MTLBO inversion (red curve in the upper graph). The lower graph illustrates the error improvement versus iteration number for noise corrupted data of the horizontal cylinder model.

curve in the upper graph). The assumed values for the horizontal cylinder model parameters and estimated ones for the noise-free and noise corrupted synthetic magnetic data are shown in Tab. 2. The processing total time taken for the noise-free and noise corrupted theoretical magnetic data of the horizontal cylinder model are 3.26462 and 3.52766 seconds, respectively.

\subsection{Composite model of a thin sheet and two spheres}

In Fig. 6, anomaly 1 is the magnetic field of a thin sheet model with the parameters $z=85 \mathrm{~m}, \theta=45^{\circ}, k=800 \mathrm{nT}$ and $q=1$, where the midpoint of the

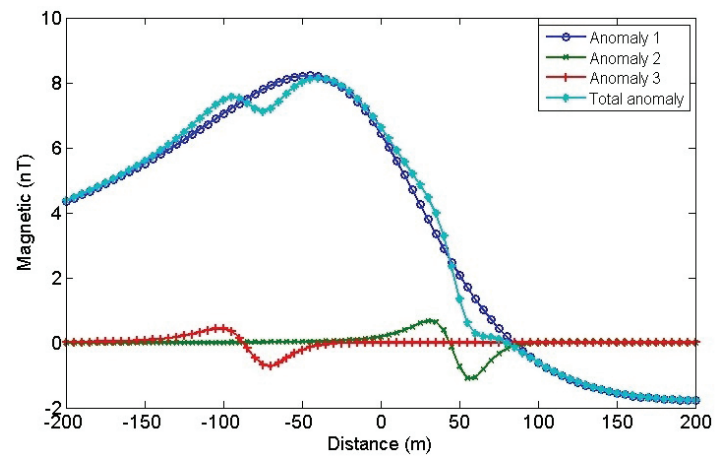

Figure 6. Total magnetic anomaly generated by a deep-seated thin sheet structure (anomaly 1) as main causative source and two neighboring sphere models (anomalies 2 and 3) as interference causative masses. 
profile $\left(x_{0}=0\right)$ is the center of model, anomaly 2 is the horizontal magnetic field of a sphere model with the parameters $z=28 \mathrm{~m}, \theta=70^{\circ}, k=18,000 \mathrm{nT}$ and $q=2.5$ and anomaly 3 is also the horizontal magnetic field of a sphere model with the parameters $z=30 \mathrm{~m}, \theta=70^{\circ}, k=18,000 \mathrm{nT}$ and $q=2.5$, where the centers of the sphere models are located in the $50 \mathrm{~m}$ and $-80 \mathrm{~m}$ from the center of the profile $\left(x_{0}=0\right)$, respectively. The anomalies 2 and 3 are the shallow interference structures which are placed around the deep intermediate structure of interest. The total magnetic anomaly is calculated by the following expression:

$$
\begin{gathered}
T\left(x_{i}, z\right)=800 \frac{85 \cdot \cos \left(45^{\circ}\right)-x_{i} \cdot \sin \left(45^{\circ}\right)}{x_{i}^{2}+7,225}+ \\
18,000 \frac{-784 \cdot \cos \left(70^{\circ}\right)-84 \cdot x_{i} \cdot \sin \left(70^{\circ}\right)+2 \cdot x_{i} \cdot \cos \left(70^{\circ}\right)}{\left(x_{i}^{2}+784\right)^{2.5}}+ \\
+18,000 \frac{-900 \cdot \cos \left(70^{\circ}\right)-90 \cdot x_{i} \cdot \sin \left(70^{\circ}\right)+2 \cdot x_{i} \cdot \cos \left(70^{\circ}\right)}{\left(x_{i}^{2}+900\right)^{2.5}} .
\end{gathered}
$$

The defined search range for the parameters of the thin sheet model is shown in Tab. 3. The black circles in the upper graph of Fig. 7 display the composite synthetic magnetic anomaly. Considering the lower graph of Fig. 7, the objective function value, $Q$, reduces intensely from its initial value of 0.053 before the first iteration to 0.0474 at the end of the $9^{\text {th }}$ iteration as this value remains stable to latest iteration. The parameter values of the inferred model using MTLBO inversion of the composite magnetic data are $z=85.46 \mathrm{~m}, \theta=45.26^{\circ}, k=805.7 \mathrm{nT}$, $q=1.03$ and $x_{0}=-0.5 \mathrm{~m}$. The inverted magnetic from the MTLBO algorithm is shown in Fig. 7 (red curve in the upper graph).

The effect of the error was examined by adding a set of random noise to the total synthetic magnetic data using the following expression:

$$
T_{\text {nois }}\left(x_{i}\right)=T_{o b s}\left(x_{i}\right)+0.8 \times(R A N(i)-0.5),
$$

Table 3. Initial assumptions and estimated numerical results for the noise-free and noise corrupted total synthetic magnetic anomaly of the combined model. The thin sheet model is desired structure.

\begin{tabular}{lcccccc}
\hline Parameter & $Q$ & $z(\mathrm{~m})$ & $\theta$ (deg.) & $k(\mathrm{nT})$ & $q$ & $x_{0}(\mathrm{~m})$ \\
\hline Assumed & - & 85 & 45 & 800 & 1 & 0 \\
Ranges & - & 60 to 110 & 25 to 65 & 400 to 1200 & 0.5 to 3 & -10 to 10 \\
Noise free & 0.0474 & 85.46 & 45.26 & 805.7 & 1.03 & -0.5 \\
Noisy data & 0.05432 & 86.21 & 45.84 & 786.5 & 0.94 & -2 \\
\hline
\end{tabular}



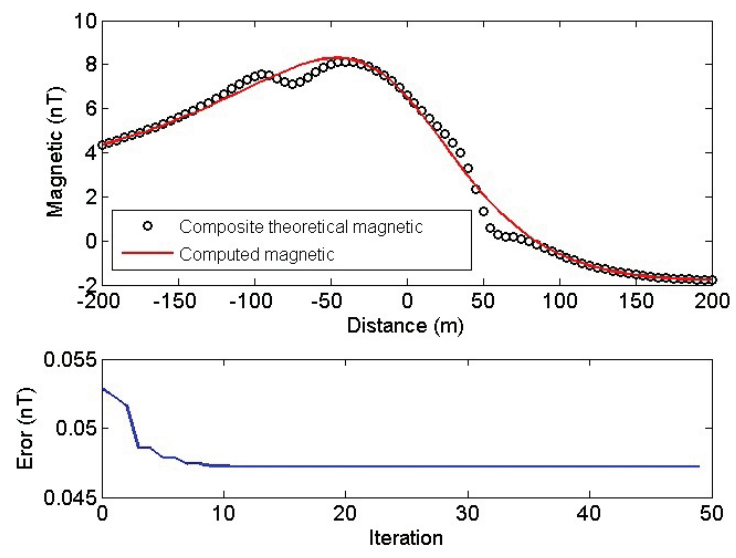

Figure 7. Total synthetic magnetic anomaly over a deep-seated thin sheet structure (anomaly 1) as main causative source and two neighboring sphere models (anomalies 2 and 3) as interference causative masses (black circles in the upper graph). The red curve in the upper graph shows the generated magnetic from the MTLBO inversion. The lower graph illustrates the error improvement versus iteration number for the composite model.

The black circles in the upper graph of Fig. 8 display the noise corrupted total theoretical magnetic anomaly. The error variations versus the iteration number show an unchanged error value of 0.05476 between the first to 3rd iterations. This value falls suddenly to 0.05445 at the end of the $4^{\text {th }}$ iteration and it reduces to 0.05432 at the end of the $17^{\text {th }}$ iteration while afterwards it remains
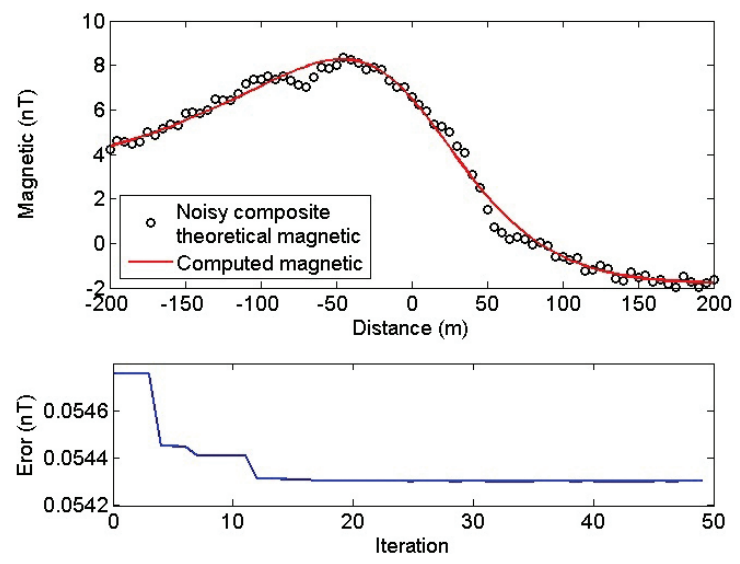

Figure 8. Noisy total synthetic magnetic anomaly over a deep-seated thin sheet structure (anomaly 1) as main causative source and two neighboring sphere models (anomalies 2 and 3) as interference causative masses (black circles in the upper graph). The red curve in the upper graph shows the generated magnetic from the MTLBO inversion. The lower graph illustrates the error improvement versus iteration number for noise corrupted data of the composite model. 
unchanged to latest iteration (Fig. 5, blue line in the lower graph). The resulted values for the noisy total magnetic anomaly using MTLBO are $z=86.21 \mathrm{~m}$, $\theta=45.84^{\circ}, k=786.5 \mathrm{nT}, q=0.94$ and $x_{0}=-2 \mathrm{~m}$. The computed magnetic anomaly due to the inferred structure from the MTLBO algorithm is shown in Fig. 8 (red curve in the upper graph). The assumed values for the thin sheet model parameters and estimated ones for the noise-free and noise corrupted total synthetic magnetic data have been brought in Tab. 3. MTLBO has been estimated the parameters values of the thin sheet model well. The processing total time taken for the noise-free and noise corrupted theoretical magnetic data of the combined model are 3.5732 and 3.8426 seconds, respectively.

\section{Field examples}

In this paper, four real magnetic data from various regions of the world are inverted using MTLBO algorithm and the computed parameters are compared with obtained results from previous evaluations that made by other inverse modeling methods.

Based on the assumed search ranges, sixty primary models are randomly considered for the causative mass of all the real magnetic anomalies data. The number of iteration and permissible error for the MTLBO algorithm are determined as 50 and 0.01 , respectively. The parameters search range for the regions under investigation are written in Tab. 4. These defined boundaries have been chosen based on the geological information and magnetic field of these area under investigation. The search range of the shape factor parameter $(q)$ is constant, i.e. $0.5 \leq q \leq 3$.

Table 4. Parameters search range in field examples.

\begin{tabular}{lccccc}
\hline Parameter & $\begin{array}{c}z \\
\text { Field example }\end{array}$ & $\begin{array}{c}\theta \\
(\mathrm{m})\end{array}$ & $\begin{array}{c}k \\
\text { (nT) }\end{array}$ & $q$ & $\begin{array}{c}x_{0} \\
(\mathrm{~m})\end{array}$ \\
\hline Parnaiba Basin, Brazil & 1 to 5 & -10 to -40 & -50 to -200 & 0.5 to 3 & 5 to 18 \\
Bankura, India & 800 to 2000 & 10 to 30 & 1000 to 5000 & 0.5 to 3 & 1500 to 3000 \\
Tabas, Iran & 40 to 80 & 35 to 60 & 30000 to 60000 & 0.5 to 3 & 100 to 200 \\
Kerman, Iran & 10 to 30 & 35 to 60 & 2000 to 5000 & 0.5 to 3 & 30 to 60 \\
\hline
\end{tabular}

\subsection{Parnaiba Basin, Brazil}

The black circles in upper graph of Fig. 9 present a total magnetic anomaly along a $20 \mathrm{~m}$ profile above and perpendicular to a Mesozoic diabase dyke intruded into Paleozoic sediments from the Parnaiba basin, Brazil (Silva, 1989). This anomaly was digitized at 41 points and with an interval of $0.5 \mathrm{~m}$. The magnetic anomaly over this dyke structure was also interpreted by several authors with different techniques, such as numerical approach (Abdelrahman et al., 2002), second derivative method (Abdelrahman and Essa, 2015) and second 

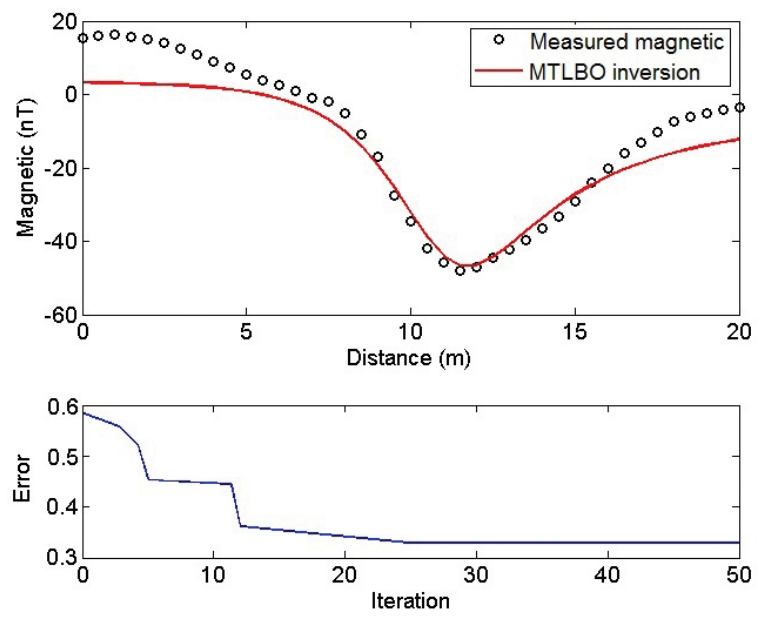

Figure 9. Observed total magnetic anomaly (black circles in the upper graphs), MTLBO inverted magnetic anomaly (red curve in the upper graphs) and error improvements versus iteration number (lower graphs) due to Mesozoic diabase dyke, Parnaiba basin, Brazil.

moving average technique (Abdelrahman et al., 2016). The estimated results from the mentioned methods are summarized in Tab. 5.

We applied the MTLBO for inverting the magnetic anomaly profile over the diabase dyke. The generated magnetic response by the inverted parameters using MTLBO (Tab. 5) is shown in the upper graph of Fig. 9 (red curve). The blue line in the lower graph of the Fig. 9 shows the objective function (error) variations in which values reduction is associated with an increase in the number of iterations. The least amount of the objective function value is 0.329 which was obtained in the $24^{\text {th }}$ iteration and this value remain invariable to latest iteration. The evaluated shape factor demonstrates that the shape of the buried structure is tabular. The evaluated depth using MTLBO is $2.86 \mathrm{~m}$ which is agree with the depth reported of $3 \mathrm{~m}$ to the magnetized part of the dyke by Silva (1989).

Table 5. Estimated parameters for mesozoic diabase dyke, Parnaiba basin, Brazil. Star sign indicates the value of $q$ has been considered as a constant.

\begin{tabular}{|c|c|c|c|c|c|c|}
\hline \multicolumn{2}{|l|}{ Parameter } & \multirow[t]{2}{*}{$\begin{array}{c}z \\
(\mathrm{~m})\end{array}$} & \multirow[t]{2}{*}{$\begin{array}{c}\theta \\
(\mathrm{deg} .)\end{array}$} & \multirow[t]{2}{*}{$\begin{array}{c}k \\
(\mathrm{nT})\end{array}$} & \multirow[t]{2}{*}{$q$} & \multirow[t]{2}{*}{$\begin{array}{l}x_{0} \\
(\mathrm{~m})\end{array}$} \\
\hline Researcher(s) & Method & & & & & \\
\hline Silva (1989) & $\begin{array}{l}\text { Transformation of nonlinear } \\
\text { problems into linear ones }\end{array}$ & 3 & - & - & - & - \\
\hline Abdelrahman et al. (2002) & Numerical approach & 3.34 & -29.6 & -74.2 & $1^{*}$ & - \\
\hline Abdelrahman and Essa (2015) & Second derivative method & 2.35 & - & - & 1.02 & - \\
\hline Abdelrahman et al. (2016) & Second moving average & 2.703 & - & - & 0.9 & - \\
\hline Present method (MTLBO) & & 2.86 & -27.2 & -128 & 0.94 & 11 \\
\hline
\end{tabular}




\subsection{Bankura, India}

The black circles in upper graph of Fig. 10 illustrate a vertical magnetic anomaly along a $4 \mathrm{~km}$ profile above a spherical mass of gabbroic composition from the Bankura area, west Bengal, India (Verma and Bandopadhyay, 1975). This anomaly was digitized at 17 points and with an interval of $0.25 \mathrm{~km}$. The magnetic anomaly over this structure was also interpreted by several authors with different techniques, such as numerical approach (Abdelrahman et al., 2002), least-squares minimization (Abdelrahman and Salem, 2005), second moving average technique (Abdelrahman et al., 2007) and second derivative method (Abdelrahman and Essa, 2015) where the estimated results from the mentioned methods are summarized in Tab. 6. We employed the MTLBO for inverting the magnetic anomaly profile over the gabbroic composition body. The generated magnetic response by the inverted parameters using MTLBO is shown by the red curve in the upper graph of Fig. 10. The blue line in the lower graph of the
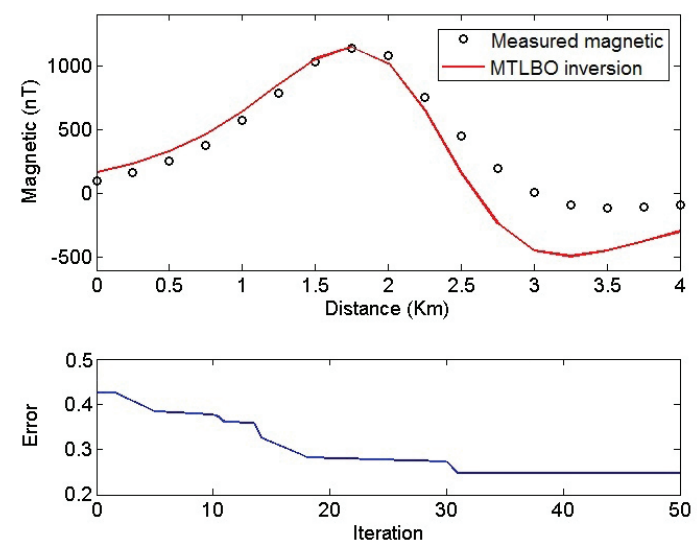

Figure 10. Observed vertical magnetic anomaly (black circles in the upper graphs), MTLBO inverted magnetic anomaly (red curve in the upper graphs) and error improvements versus iteration number (lower graphs) due to the gabbroic composition from the Bankura area, west Bengal, India.

Table 6. Estimated parameters for the gabbroic composition from the Bankura area, west Bengal, India. Star indicates the value of $q$ that has been considered as a constant.

\begin{tabular}{|c|c|c|c|c|c|c|}
\hline \multicolumn{2}{|l|}{ Parameters } & \multirow[t]{2}{*}{$\begin{array}{c}z \\
(\mathrm{~km})\end{array}$} & \multirow[t]{2}{*}{$\begin{array}{c}\theta \\
\text { (deg.) }\end{array}$} & \multirow[t]{2}{*}{$\begin{array}{c}k \\
(\mathrm{nT})\end{array}$} & \multirow[t]{2}{*}{$q$} & \multirow[t]{2}{*}{$\begin{array}{c}x_{0} \\
(\mathrm{~km})\end{array}$} \\
\hline Researcher(s) & Method & & & & & \\
\hline Abdelrahman et al. (2002) & Numerical approach & 1.47 & 55 & 29,089 & $2.5^{*}$ & - \\
\hline Abdelrahman and Salem (2005) & Least-squares minimization & 1.37 & 53.1 & 25,212 & $2.5^{*}$ & - \\
\hline Abdelrahman et al. (2007) & Second moving average & 1.457 & - & - & $2.5^{*}$ & - \\
\hline Abdelrahman and Essa (2015) & Second derivative method & 1.43 & - & - & 2.58 & - \\
\hline Present method (MTLBO) & & 1.453 & 31.83 & 3,167 & 2.61 & 2.25 \\
\hline
\end{tabular}


Figure 10 shows the objective function (error) variations in which the minimum error with a value of 0.258 was estimated at the end of the $31^{\text {th }}$ iteration and this value remain constant to latest iteration. The estimated parameters at the 31 th iteration as the best solutions are brought in Tab. 6. The evaluated inclination angle shows a good coincidence with the geomagnetic inclination angle of the Bankura region.

\subsection{Field examples from Iran}

Two dimensional variations of the magnetic fields related to two areas under consideration situated in east of Iran, namely Tabas and Kerman are shown by the black circles in upper graphs of Figs. 11 and 12, respectively. These regions
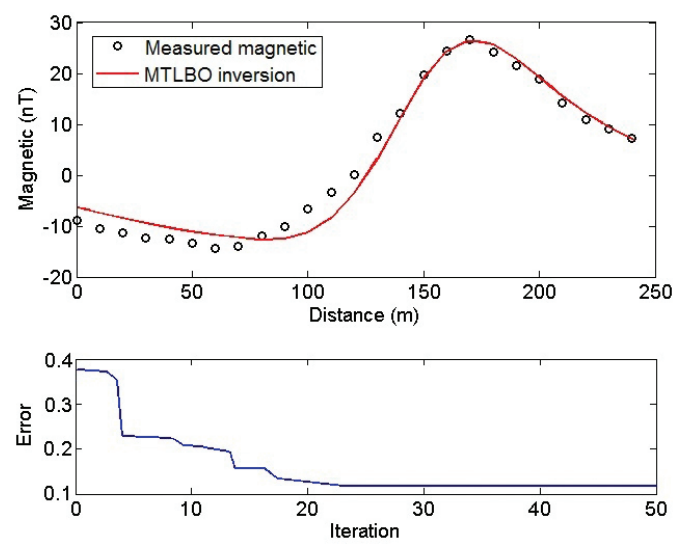

Figure 11. Observed vertical magnetic anomaly (black circles in the upper graphs), MTLBO inverted magnetic anomaly (red curve in the upper graphs) and error improvements versus iteration number (lower graphs) due to the Magnetite deposit from the Tabas area, Iran.
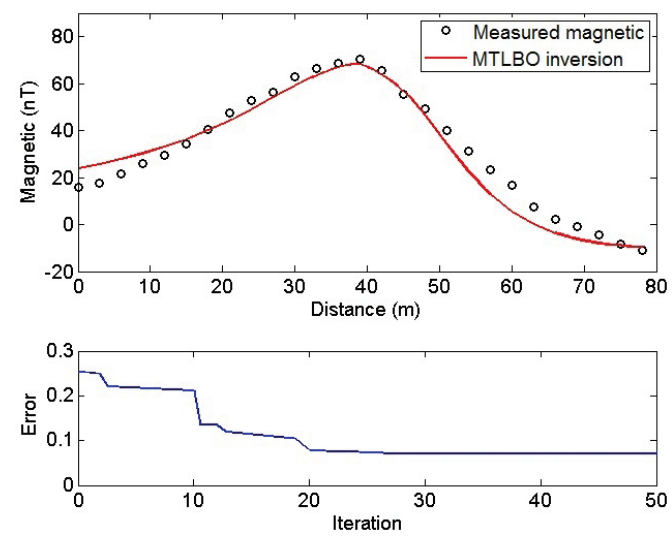

Figure 12. Observed vertical magnetic anomaly (black circles in the upper graphs), MTLBO inverted magnetic anomaly (red curve in the upper graphs) and error improvements versus iteration number (lower graphs) due to the Magnetite deposit from the Kerman area, Iran. 
are significant for their iron ores deposits potential such as Magnetite. The magnetic data measurement for the Tabas area was done at 25 points along $240 \mathrm{~m}$ profile with an interval of $10 \mathrm{~m}$ and for Kerman area was sampled at 27 points along $78 \mathrm{~m}$ profile with an interval of $3 \mathrm{~m}$. The estimated structure parameters using MTLBO algorithm for the Tabas area are $z=68.4 \mathrm{~m}, \theta=50.8^{\circ}, k=46,700 \mathrm{nT}$, $q=1.87$ and $x_{0}=150 \mathrm{~m}$ and for the Kerman area are $z=17.9 \mathrm{~m}, \theta=44.7^{\circ}$, $k=3,162 \mathrm{nT}, q=1.07$ and $x_{0}=45 \mathrm{~m}$ as have been written in Tab. 7. Based on

Table 7. Estimated parameters for the Magnetite deposits from the Tabas and Kerman areas, east of Iran.

\begin{tabular}{llccccc}
\hline Parameter & & $\begin{array}{c}z \\
(\mathrm{~m})\end{array}$ & $\begin{array}{c}\theta \\
(\mathrm{deg} .)\end{array}$ & $\begin{array}{c}k \\
(\mathrm{nT})\end{array}$ & $q$ & $\begin{array}{c}x_{0} \\
(\mathrm{~m})\end{array}$ \\
\hline $\begin{array}{l}\text { Present method } \\
(\mathrm{MTLBO})\end{array}$ & Tabas & 68.4 & 50.8 & 46700 & 1.87 & 150.7 \\
& Kerman & 17.9 & 44.7 & 3162 & 1.07 & 45.3 \\
\hline
\end{tabular}

the computed shape factors, the geometric shape of the anomaly causative mass in the Tabas and Kerman areas can simulate the horizontal cylinder and sheet (dyke structure), respectively. The inverted magnetic fields according to the estimated parameters for both case studies are represented by the red curve in upper graphs of Figs. 11 and 12.

Considering the error variation versus iteration number for both areas under investigation (lower graphs in Figs. 11 and 12), the minimum values of the objective function for the Tabas site is 0.121 and for the Kerman site is 0.073. These objective function values for the Tabas and Kerman sites were obtained in the $23^{\text {th }}$ iteration and $27^{\text {th }}$ iteration, respectively as these values remain invariable to latest iteration.

\section{Conclusions}

The MTLBO algorithm is indeed a machine learning algorithm and population-based approach. we have developed this method to interpret the theoretical and real magnetic data in an iterative process as can estimates the model unknown parameters, simultaneously. In fact, the MTLBO algorithm is a nonlinear inversion modeling method. Solving a system of nonlinear equations with some unknown parameters with common methods, such as least square without an or some initial guesses is impossible. Using optimization approaches based on artificial intelligence are the best strategy for solving these problems. In this paper, we have introduced the multivariable teaching-learning-based optimization (MTLBO) algorithm for interpreting the residual magnetic data caused by the simple geometry shapes.

The MTLBO inversion has some advantages in comparison with the previous interpretation techniques which we have discussed in this study. The MTLBO is able to estimate five parameters, i.e. the depth $(z)$, amplitude coefficient $(k)$, 
shape factor $(q)$, angle of effective magnetization $(\theta)$ and axis location $\left(x_{0}\right)$ simultaneously in a very short time with a satisfactory accuracy. Moreover, if the MTLBO be employed for a magnetic data set several times, the responses are always equal.

In MTLBO algorithm, each variable or parameter has its own individual teacher which is presumed to be a highly learned person and assigned as the best learner or solution. The enhancement of the accuracy of the solutions in learner phase is performed by a reciprocal interaction between two learners which are randomly chosen.

The selection of the appropriate ranges for the model parameters is related mainly to the obtained residual magnetic field after processing of the measured magnetic data.

Although, the MTLBO is a flexible and dynamic algorithm and for each range of the parameters converges to the optimal solutions, provided that the defined ranges include the value of structure parameters, having geological information and other geophysical methods results can be useful for choosing the optimal ranges until the consumed time for inverting decreases.

The proposed technique has been firstly examined on theoretical magnetic data sets, with and without added random noise, as the inferred model parameters simulate almost the assumed ones. The evaluated error for the noise-free synthetic magnetic anomalies related to the sphere and horizontal cylinder models are 0.00085 and 0.00066 , respectively. By adding the random noise to the theoretical magnetic data, objective function values are increased to 0.109 and 0.119 , respectively. The proficiency of the MTLBO was investigated by a composite model consisting of a deep-seated thin sheet structure as main causative source and two shallow neighboring sphere models as interference causative masses, as the inferred structure coincides closely with the main assumed one. The MTLBO was also applied for inverting several real magnetic anomaly profiles. Analysis of real field magnetic anomalies related to the Parnaiba basin, Brazil and Bankura area, India shows that the estimated parameters are close the other researchers results as shown in Tabs. 6 and 7. The processing total times taken for the Parnaiba basin, Bankura, Tabas and Kerman areas using MTLBO are $3.46238 \mathrm{sec}, 3.62345 \mathrm{sec}, 3.36271 \mathrm{sec}$ and $3.56214 \mathrm{sec}$, respectively.

The advantage of the MTLBO algorithm, as a powerful and intelligent optimization tool, is that it can estimate the best permanent solutions very fast without falling into local minimum. This method is able to achieve the optimal responses even if a small population of learners are considered.

\section{References}

Abdelrahman, E. M., Abdelazeem, M. and Gobashy, M. (2019): A minimization approach to depth and shape determination of mineralized zones from potential field data using the Nelder-Mead simplex algorithm, Ore Geol. Rev., 114, 103-123, https://doi.org/10.1016/j.oregeorev.2019.103123. 
Abdelrahman, E. M., Abo-Ezz, E. R. and Essa, K. S. (2012): Parametric inversion of residual magnetic anomalies due to simple geometric bodies, Explor. Geophys., 43, 178-189, https://doi. org/10.1071/EG11026.

Abdelrahman, E. M., Abo-Ezz, E. R., Essa, K. S., El-Araby, T. M. and Soliman, K. S. (2007): A new least-squares minimization approach to depth and shape determination from magnetic data, Geophys. Prospect., 55, 433-446, https://doi.org/10.1007/s00024-015-1168-9

Abdelrahman E. M., El-Araby, H. M., El-Araby, T. M. and Essa, K. S. (2002): A new approach to depth determination from magnetic anomalies, Geophysics, 67, 1524-1531, https://doi. org/10.1190/1.1512748.

Abdelrahman, E. M., El-Araby, H. M., El-Araby, T. M. and Essa, K. S. (2003): A least-squares minimization approach to depth determination from magnetic data, Pure Appl. Geophys., 160, 1259-1271, https://doi.org/10.1007/s000240300005.

Abdelrahman, E. M. and Essa, K. S. (2005): Magnetic interpretation using a least-squares, depthshape curves method, Geophysics, 70, L23-L30, https://doi.org/10.1190/1.1926575.

Abdelrahman, E. M. and Essa, K. S. (2015): A new method for depth and shape determinations from magnetic data, Pure Appl. Geophys., 172, 439-460, https://doi.org/10.1007/s00024-014-0885-9.

Abdelrahman, E. M., Essa, K. S., El-Araby, T. and Abo-Ezz, E. R. (2016): Depth and shape solutions from second moving average residual magnetic anomalies, Explor. Geophys., 47, 58-66, https:// doi.org/10.1071/EG14073.

Abdelrahman, E. M. and Salem, A. (2005): A least-squares minimization approach to depth determination from numerical horizontal magnetic gradients, Kuwait J. Sci. Eng., 22, 103-118.

Abdelrahman, E. M., Soliman, K. S., El-Araby, T. M., Abo-Ezz, E. R. and Essa, K. S. (2009): A leastsquares standard deviation method to interpret magnetic anomalies due to thin dykes, Near Surf. Geophys., 7, 41-46, https://doi.org/10.3997/1873-0604.2008032.

Abedi, M., Gholami, A. and Norouzi, G. H. (2013): A stable downward continuation of airborne magnetic data: A case study for mineral prospectivity mapping in Central Iran, Comput. Geosci., 52, 269-280, https://doi.org/10.1016/j.cageo.2012.11.006.

Abo-Ezz, E. R. and Essa, K. S. (2016): A least-squares minimization approach for model parameters estimate by using a new magnetic anomaly formula, Pure Appl. Geophys., 173, 1265-1278, https:// doi.org/10.1007/s00024-015-1168-9.

Asfahani, J. and Tlas, M. (2004): Nonlinearly constrained optimization theory to interpret magnetic anomalies due to vertical faults and thin dykes, Pure Appl. Geophys., 161, 203-219, https:// doi.org/10.1007/s00024-003-2433-x.

Asfahani, J. and Tlas, M. (2007): A robust nonlinear inversion for the interpretation of magnetic anomalies caused by faults, thin dykes and spheres like structure using stochastic algorithms, Pure Appl. Geophys., 164, 2023-2042, https://doi.org/10.1007/s00024-007-0254-z.

Balkaya, C., Ekinci, Y. L., Göktürkler, G. and Turan, S. (2017): 3D non-linear inversion of magnetic anomalies caused by prismatic bodies using differential evolution algorithm, J. Appl. Geophys., 136, 372-386, https://doi.org/10.1016/j.jappgeo.2016.10.040.

Birashk, A., Kordestani, J. K. and Meybodi, M. R. (2018): Cellular teaching-learning-based optimization approach for dynamic multi-objective problems, Knowl-Based Syst., 141, 148-177, https:// doi.org/10.1016/j.knosys.2017.11.016.

Biswas, A. (2016): Interpretation of gravity and magnetic anomaly over thin sheet-type structure using very fast simulated annealing global optimization technique, Model. Earth Syst. Environ., 2, 30, https://doi.org/10.1007/s40808-016-0082-1.

Biswas, A., Parija, M. P. and Kumar, S. (2017): Global nonlinear optimization for the interpretation of source parameters from total gradient of gravity and magnetic anomalies caused by thin dyke, Ann. Geophys., 60, G0218, p. 17, https://doi.org/10.4401/ag-7129.

Biswas, A. (2018): Inversion of source parameters from magnetic anomalies for mineral/ore deposits exploration using global optimization technique and analysis of uncertainty, Nat. Resour. Res., 27, 77-107, https://doi.org/10.1007/s11053-017-9339-2. 
Chen, D., Zou, F., Li, Z., Wang, J. and Li, S. (2015): An improved teaching-learning-based optimization algorithm for solving global optimization problem, Inf. Sci., 297, 171-190, https://doi. org/10.1016/j.scient.2012.12.005.

Chen, D., Zou, F., Wang, J. and Yuan, W. (2015): SAMCCTLBO: A multi-class cooperative teachinglearning-based optimization algorithm with simulated annealing, Soft Comput., 1-23, https://doi. org/10.1007/s00500-015-1613-9.

Cooper, G. R. J. (2012): The semi-automatic interpretation of magnetic dyke anomalies, Comput. Geosci., 44, 95-99, https://doi.org/10.1016/j.cageo.2012.02.016.

Di Maio, R., Rani, P., Piegari, E. and Milano, L. (2016): Self potential data inversion through a genetic-price algorithm, Comput. Geosci., 94, 86-95, https://doi.org/10.1016/j.cageo.2016.06.005.

Ekinci, Y. L., Balkaya, C. and Göktürkler, G. and Turan, S. (2016): Model parameter estimations from residual gravity anomalies due to simple-shaped sources using differential evolution algorithm, J. Appl. Geophys., 129, 133-147, https://doi.org/10.1016/j.jappgeo.2016.03.040.

Ekinci, Y. L., Balkaya, C., Göktürkler, G. (2020): Global optimization of near-surface potential field anomalies through metaheuristics, in: Advances in modeling and interpretation in near surface geophysics, edited by: Biswas, A. and Sharma, S. P. Springer, Cham, 155-188 pp, https://doi. org/10.1007/978-3-030-28909-6_7.

Eshaghzadeh, A. and Kalantary, R. A. (2016): Magnetic field interpretation using singular value decomposition method based on correlation coefficient of eigenimages, J. Biodivers. Environ. Sci., 9, 185-193.

Eshaghzadeh, A., Sahebari, S. S. and Kalantari, R. A. (2020): Determination of sheet-like geological structures parameters using Marquardt inversion of the magnetic data, Indian J. Geo-Mar. Sci., 49, 450-457, http://nopr.niscair.res.in/handle/123456789/54419.

Essa, K. S. and Elhussein, M. (2017a): A new approach for the interpretation of magnetic data by a 2-D dipping dyke, J. Appl. Geophys., 136, 431-443, https://doi.org/10.1016/j.jappgeo.2016.11.022.

Essa, K. S. and Elhussein, M. (2017b): 2D dipping dyke magnetic data interpretation using a robust particle swarm optimization, Geosci. Instrum. Method. Data Syst. Discuss., https://doi.org/10.5194/ gi-2017-39.

Essa, K. S. and Elhussein, M. (2018): PSO (Particle Swarm Optimization) for interpretation of magnetic anomalies caused by simple geometrical structures, Pure Appl. Geophys., 175, 3539-3553, https://doi.org/10.1007/s00024-018-1867-0.

Essa, K. S. and Elhussein, M. (2020): Interpretation of magnetic data through particle swarm optimization: Mineral exploration cases studies, Nat. Resour. Res., 29, 521-537, https://doi.org/10.1007/ s11053-020-09617-3.

Jain, S. (1976): An automatic method of direct interpretation of magnetic profiles, Geophysics, 41, p. 531, https://doi.org/10.1190/1.1440631.

Kumar, Y. (2019): A new variant of teaching-learning-based optimization algorithm for global optimization problems, Informatica, 43, 65-75, https://doi.org/10.31449/inf.v43i1.1636.

Prakash, T., Singh, V. P., Singh, S. P. and Mohanty, S. R. (2018): Economic load dispatch problem: quasi-oppositional self-learning TLBO algorithm, Energ. Syst., 9, 415-438, https://doi.org/10.1007/ s12667-017-0230-3.

Reid, A. B., Allsop, J. M., Gramser, H., Millett, A. J. and Somerton, I. W. (1990): Magnetic interpretation in three dimensions using Euler deconvolution, Geophysics, 55, p. 90, https://doi. org/10.1190/1.1442774.

Rao, R. V. (2016): Review of applications of TLBO algorithm and a tutorial for beginners to solve the unconstrained and constrained optimization problems, Dec. Sci. Lett., 5, 1-30, https://doi. org/10.5267/j.dsl.2015.9.003.

Rao, R. V. and Patel, V. (2013a): Comparative performance of an elitist teaching-learning-based optimization algorithm for solving unconstrained optimization problems, Int. J. Ind. Eng. Comput., 4, 29-50, https://doi.org/10.5267/j.ijiec.2012.09.001.

Rao, R. V. and Patel, V. (2013b): Multi-objective optimization of two stage thermoelectric cooler using a modified teaching-learning-based optimization algorithm, Eng. Appl. Artif. Intell., 26, 430-445, https://doi.org/10.1016/j.engappai.2012.02.016. 
Rao, R. V. and Patel, V. (2013c): Multi-objective optimization of heat exchangers using a modified teaching-learning-based optimization algorithm, Appl. Math. Model., 37, 1147-1162, https:/doi. org/10.1016/j.apm.2012.03.043.

Rao, R. V. and Patel, V. (2014): A multi-objective improved teaching-learning-based optimization algorithm for unconstrained and constrained optimization problems, Int. J. Ind. Eng. Comput., 5, 1-22, https://doi.org/10.5267/j.ijiec.2013.09.007.

Rao, R., Savsani, V., and Vakharia, D. (2011): Teaching-learning-based optimization: A novel method for constrained mechanical design optimization problems, IEEE Trans. Comput. Aided. Des., 43, 303-315, https://doi.org/10.1016/j.cad.2010.12.015.

Satapathy, S. C. and Naik, A. (2014): Modified teaching-learning-based optimization algorithm for global numerical optimization - A comparative study, Swarm Evol. Comput., 16, 28-37, https:// doi.org/10.1016/j.swevo.2013.12.005.

Silva, J. B. C. (1989): Transformation of nonlinear problems into linear ones applied to the magnetic field of a two-dimensional prism, Geophysics, 54, 114-121, https://doi.org/10.1190/1.1442568.

Srivastava, S., Datta, D., Agarwal, B. N. P. and Mehta, S. (2014): Applications of ant colony optimization in determination of source parameters from total gradient of potential fields, Near Surf. Geophys., 12, 373-389, https://doi.org/10.1002/nsg.123001.

Thompson, D. T. (1982): EULDPH A new technique for making computer-assisted depth estimates from magnetic data, Geophysics, 47, p. 31, https://doi.org/10.1190/1.1441278.

Tlas, M. and Asfahani, J. (2015): The simplex algorithm for best estimate of magnetic parameters related to simple geometric shaped structures, Math. Geosci., 47, 301-316, https://doi.org/10.1007/ s11004-014-9549-7.

Tlas, M. and Asfahani, J. (2018): Interpretation of magnetic anomalies due to simple geometricshaped structures based on quadratic curve regression, Contrib. Geophys. Geodesy, 48, 161-178, https://doi.org/10.2478/congeo-2018-0006.

Verma, R. K. and Bandopadhyay, R. R. (1975): A magnetic survey over Bankura Anorthosite complex and surrounding areas, Indian J. Earth Sci., 2, 117-124.

Wang, L., Zou, F., Hei, X., Yang, D., Chen, D. and Jiang, Q. (2014): an improved teaching-learningbased optimization with neighborhood search for applications of ANN, Neurocomputing, 143, 231-247, https://doi.org/10.1016/j.neucom.2014.06.003.

Yu, K., Wang, X. and Wang, Z. (2015): Self-adaptive multi-objective teaching-learning-based optimization and its application in ethylene cracking furnace operation optimization, Chem. Intell. Lab. Syst., 146, 198-210, https://doi.org/10.1016/j.chemolab.2015.05.015.

Yu, K., Wang, X. and Wang, Z. (2016): Constrained optimization based on improved teaching-learning-based optimization algorithm, Inform. Sciences, 352, 61-78, https://doi.org/10.1016/j. ins.2016.02.054.

Zheng, H. Y., Wang, L. and Zheng, X. L. (2017): Teaching-learning-based optimization algorithm for multi-skill resource constrained project scheduling problem, Soft Comput., 21, 1537-1548, https:// doi.org/10.1007/s00500-015-1866-3. 


\title{
SAŽETAK
}

\section{Multivarijabilni algoritam optimizacije podučavanjem-učenjem (MTLBO) za procjenu strukturnih parametara podzemnih objekata pomoću magnetskih podataka}

\author{
Ata Eshaghzadeh i Sanaz Seyedi Sahebari
}

U ovom radu je predstavljen prirodno utemeljen multivarijabilni algoritam optimizacije poučavanjem-učenjem (MTLBO). MTLBO algoritam tijekom iterativnog postupka može procijeniti najbolje vrijednosti parametara podzemnih struktura (model) u višepredmetnom problemu. Algoritam djeluje u dvije računske faze: fazi učitelja i fazi učenika. Glavna svrha algoritma MTLBO je mijenjati naučene vrijednosti te poboljšavajući tako vrijednosti parametara modela dovesti do optimalnog rješenja. Varijable svakog učenika (model) su: dubina $(z)$, koeficijent amplitude $(k)$, faktor oblika $(q)$, kut učinkovite magnetizacije $(\theta)$ i parametri osi $\left(x_{0}\right)$. U radu je korištena MTLBO metoda na podacima magnetskih anomalija uzrokovanih podzemnim strukturama jednostavnog geometrijskog oblika, poput sfere i vodoravno postavljenog cilindra. Učinkovitost MTLBO metode također je proučavana na šumom kontaminiranim sintetičkim podacima, budući da su dobiveni prihvatljivi rezultati. MTLBO metoda je primijenjena za interpretaciju četiri profila magnetske anomalije u Iranu, Brazilu i Indiji.

Ključne riječi: magnetski, MTLBO algoritam, optimizacija, multi-objektni problem

Corresponding author's address: Ata Eshaghzadeh, Department of Geology, Faculty of Sciences, University of Isfahan, Isfahan, Iran; e-mail: eshagh@alumni.ut.ac.ir (ORCID: 0000-0003-0665-0517).

(cc) BY-NC This work is licensed under a Creative Commons Attribution-NonCommercial 4.0 International License. 